\title{
La configuración de un sistema de espacios de representación patrimonial en Loja
}

A partir de la segunda mitad de los años 80 , y especialmente en la década de los 90 del siglo reciente, las ciudades medias del interior de Andalucía comienzan a experimentar un importante proceso de recuperación demográfica, social y económica, que conlleva una mejora sensible en las condiciones de vida de sus habitantes, así como en sus expectativas de desarrollo.

La ejecución de importantes inversiones públicas en infraestructuras y equipamientos, la diversificación productiva hacia los sectores secundario y de servicios, la iniciativa renovada de los agentes económicos y sociales locales -apoyada con programas de desarrollo territorial vinculados a la UE -, etc., ha propiciado una dinámica de progreso en la que la puesta en valor de los recursos patrimoniales locales (tanto naturales como culturales) representa un papel relevante.

En este contexto debemos enmarcar el programa de "equipamientos de representación patrimonial" que viene desarrollándose en Loja desde el año 2002 y que pretende difundir, a través de los siguientes elementos, los más destacados valores culturales y ambientales del territorio.

\section{$\rightarrow$ Centro de Interpretación Histórico de Loja}

Inaugurado en 2002, instalado en la antigua Casa de Cabildos (s. XVI), en plena Plaza de la Constitución, y financiado con fondos del programa Leader $(84000 €)$, actúa como oficina de atención turística principal. Producido por el Área de Cultura y gestionado desde el Patronato Municipal de Turismo, su espacio expositivo (en torno a $120 \mathrm{~m}^{2}$ ) se articula en seis pequeñas áreas interactivas, en las que se desarrolla la historia de la localidad con un criterio cronológico, hasta concluir la visita en una sala de audiovisuales.

\section{$\rightarrow$ Museo Histórico Municipal de la Alcazaba (MHA)}

Inaugurado en 2004, en la Casa de los Alcaides Cristianos del conjunto de la Alcazaba (s. XVII), su proceso de producción museográfica contó, básicamente, con financiación procedente de la Consejería de Turismo de la Junta de Andalucía y Caja Granada (190000€) -la restauración del edificio fue financiada por el Ayuntamiento de Loja y el Programa de Escuelas Taller (INEM)-. Presenta una interesante colección de materiales históricos de naturaleza diversa, organizada con un criterio temático en cinco áreas, que a su vez se articulan en 21 ámbitos expositivos. Ofrece $265 \mathrm{~m}^{2}$ totales de superficie expositiva y está gestionado por el Área de Cultura del Ayuntamiento.

El MHA ha iniciado este año 2007 su primer programa de ampliación, que conlleva la restauración y musealización del ajibe del patio de armas (con la financiación del Ministerio de Cultura), así como de la Torre del Homenaje, con la instalación, en su planta superior, de una "cámara oscura". La inversión global prevista asciende a 790 000€, para lo que se cuenta con el apoyo económico principal del Plan Turístico de Ciudades Medias del Centro de Andalucía.

\section{$\rightarrow$ Centro de Interpretación Ambiental de Riofrio}

Ubicado en el inmueble de "Villa Carmen" del pequeño núcleo de población de Riofrío (anejo de Loja), funciona desde 2004 como centro de atención al visitante riofrieño. Cuenta con una pequeña superficie expositiva próxima a los $100 \mathrm{~m}^{2}$, además de una sala de usos múltiples y un entorno ajardinado al aire libre. La empresa Geosur desarrolla su programa didáctico "aula de la naturaleza", siendo el Patronato Municipal de Turismo de Loja el encargado de la gestión de visitas.

\section{$\rightarrow$ Centro de Interpretación del agua}

Equipamiento en proceso de ejecución en la margen izquierda del río Genil, instalado en un edificio de arquitectura rabiosamente contemporánea que albergará un área expositivo/interpretativa temática en torno al agua, además de espacios polivalentes, biblioteca especializada y laboratorio de experimentación y análisis. El proyecto tiene previsto su finalización a finales de 2008. La inversión global ronda los 450 675€, con la participación financiera preferente del citado Plan Turístico.

En el programa de equipamientos esbozado confluye el trabajo de los departamentos municipales de Cultura y Medio Ambiente del Ayuntamiento de Loja, del Patronato Municipal de Turismo de la localidad, así como de la Fundación Ibn al-Jatib de Estudios y Cooperación Cultural (Ayuntamiento de Loja-Diputación Provincial), que desarrolla los programas anuales de investigación sobre temas locales, publicaciones y jornadas técnicas. 
D Detalles de las distintas salas del Museo Municipal de la Alcazaba de Loja (Granada) /
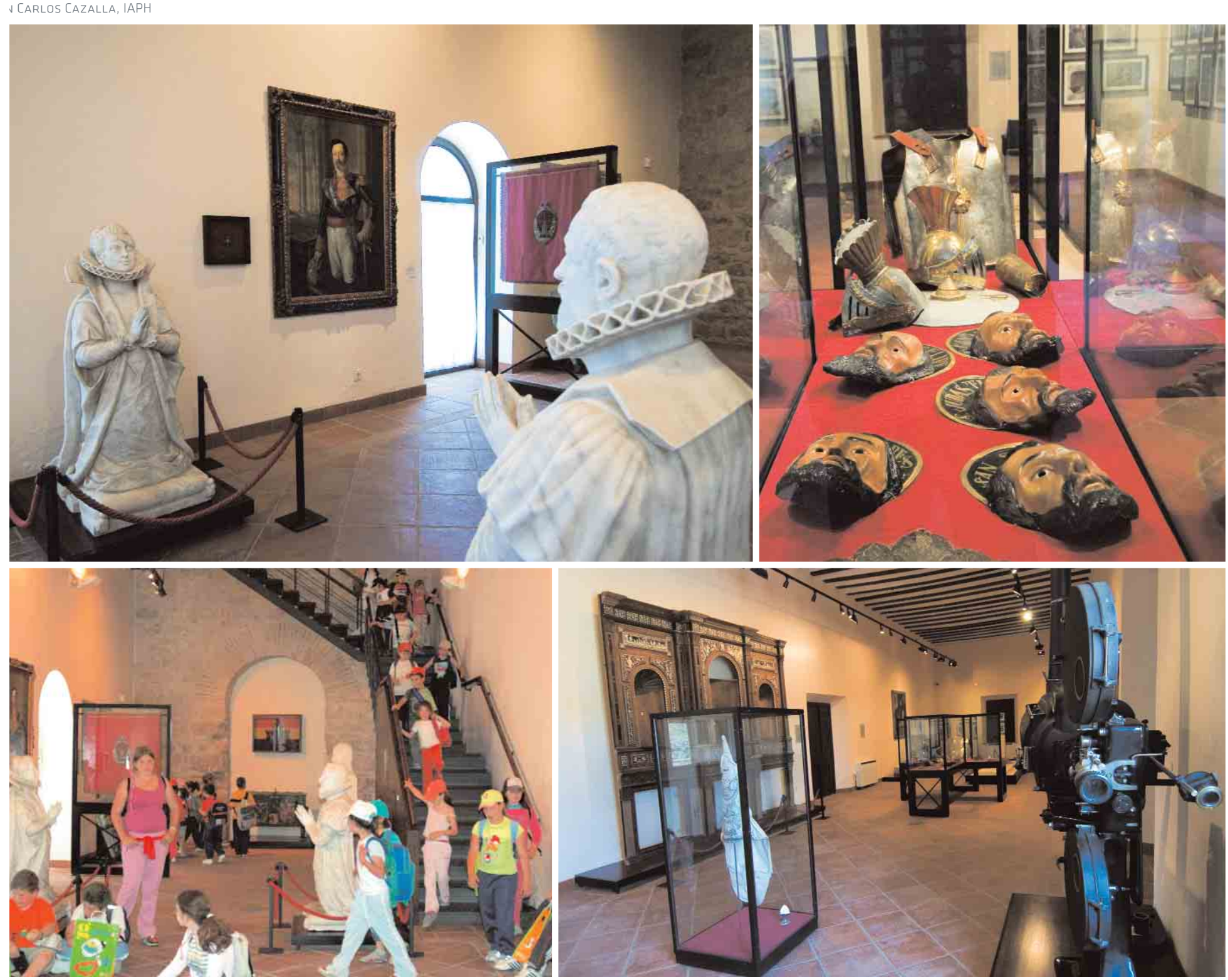

(1) Niños visitando el Museo

(1) Detalles de las distintas salas del Museo Municipal de la Alcazaba de Loja (Granada) 